\title{
Predição da digestibilidade da matéria seca de rações em coelhos em crescimento
}

\author{
Paulo Sérgio dos Santos Teixeira ${ }^{1}$, Francisco Stefano Wechsler ${ }^{2}$, Ana Silvia Alves Meira \\ Tavares Moura ${ }^{2}$
}

\footnotetext{
1 Universidade Estadual Paulista UNESP, Seção de Biotério, Campus de Botucatu, 18618-000, Botucatu, SP

2 Universidade Estadual Paulista UNESP, Faculdade de Medicina Veterinária e Zootecnia, Departamento de Produção Animal, Caixa Postal 560, 18618-970.
}

RESUMO - O experimento foi realizado com o objetivo de predizer a digestibilidade da matéria seca (MS) de rações para coelhos em crescimento mediante equações baseadas no conceito de entidade nutritiva ideal. Foram usados 100 coelhos do Grupo Genético Botucatu, com 42 dias de idade. Testaram-se 16 rações contendo alimentos volumosos (papel, sabugo de milho, bagaço de cana ou maravalha de pínus), mais milho, farelo de soja, óleo de soja, caulim e sal comum. Os volumosos foram incluídos em quatro níveis, para se obter 22, 28, 34 ou 40\% de fibra em detergente neutro (FDN) e 16\% de proteína bruta (PB). O experimento foi realizado em duas fases, em delineamento experimental de blocos ao acaso. Observou-se efeito linear positivo da FDN sobre o consumo de MS. As médias de digestibilidade da MS variaram entre 60,10 e 80,78\%. Houve efeito linear negativo da FDN, bem como interação do teor de FDN $\times$ volumoso, sobre a digestibilidade aparente da MS. Ao contrário dos componentes fibrosos, a proteína bruta PB e o conteúdo celular comportaram-se como entidade nutritiva ideal. Para predizer a digestibilidade da MS, testaram-se três modelos e o melhor baseou-se no teor de conteúdo celular, com digestibilidade verdadeira fixada em 1 ; outro no teor de FDN, cuja digestibilidade foi predita mediante uma equação empírica; e o terceiro, na perda endógena de conteúdo celular, considerada proporcional ao consumo de MS. A principal dificuldade na formulação de modelos para predizer a digestibilidade aparente da MS em coelhos é estimar com precisão a digestibilidade da FDN e a perda endógena de conteúdo celular. É necessário avaliar em estudos futuros o uso de maiores níveis de fibra nas rações. Para rações com níveis de fibra situados na amplitude deste estudo, recomenda-se usar o modelo 3, que inclui, além da fibra em detergente neutro, a fibra em detergente ácido e a lignina.

Palavras-chave: conteúdo celular, equações, fibra em detergente ácido, fibra em detergente neutro, nutrição, proteína bruta

\section{Prediction of dry matter digestibility of diets in growing rabbits}

ABSTRACT - The experiment was conducted with the objective of predicting the dry matter (DM) digestibility of rations for growing rabbits, by means of equations based on the concept of ideal nutritive entity. One hundred 42-day-old rabbits from the Botucatu Genetic Group were used. Sixteen rations were tested, containing roughage (paper, corn cobs, sugarcane bagasse or pine shavings), plus corn, soybean meal, soybean oil, kaolin and common salt. Roughages were included at four levels, to obtain 22, 28, 34 or $40 \%$ neutral detergent fiber (NDF) and $16 \%$ crude protein (CP). The experiment was accomplished in two periods, in a randomized block design. Positive linear effect of NDF on DM intake was observed. The means of DM digestibility varied between 60.10 and $80.78 \%$. There was a negative linear effect of NDF, as well as of the NDF content $\times$ roughage interaction on the DM apparent digestibility. Both CP and cell contents behaved as ideal nutritive entity, but the fibrous components did not. To predict DM digestibility, three models were tested; the best model was based on the cell contents, with true digestibility fixed at 1; another on the NDF content, whose digestibility was predicted by means of an empiric equation; and the third one on the endogenous loss of cell contents. The main difficulty in the formulation of models for apparent DM digestibility prediction is to estimate, with precision, NDF digestibility and cell contents endogenous loss. Future studies evaluating higher fiber levels in the diets are needed. For diets with fiber content within the range tested in the present study, model 3, which includes, besides neutral detergent fiber, acid detergent fiber and lignin, is recommended.

Key Words: acid detergent fiber, cell content, crude protein, equations, neutral detergent fiber, nutrition 


\section{Introdução}

O coelho possui intestino grosso desenvolvido, notadamente o ceco. A existência de flora microbiana ativa no ceco resulta em alta capacidade relativa, em comparação à de suínos e aves, de aproveitar alimentos fibrosos. Essa capacidade, todavia, não se equipara à dos ruminantes (Cheeke, 1987; Ferreira et al., 2006).

Vários autores enfatizaram a importância da fibra na prevenção de enterites e hipomotilidade do trato intestinal de coelhos (Gidenne, 2003). A digestibilidade e o teor de energia digestível dos alimentos estão estreitamente relacionados ao seu teor de fibra. Baixos níveis de fibra resultam em maiores teores de energia digestível e maiores ganhos de peso, porém acarretam maior incidência de enterites e altas taxas de mortalidade. Por outro lado, altos níveis de fibra reduzem a mortalidade, porém, simultaneamente, diminuem a ingestão de matéria seca e o ganho de peso (Gidenne et al., 1998).

A composição da fração fibrosa, ou seja, a proporção dos componentes da parede celular, especialmente lignina, é importante na determinação da digestibilidade. A predição da digestibilidade pode ser feita tanto por meio de equações de regressão empíricas quanto por modelos com base biológica. Lucas, citado por Van Soest (1993), propôs o conceito de "entidade nutritiva ideal”. Para verificar se determinado componente químico é uma "entidade nutritiva ideal”, realiza-se uma regressão do teor de componente digestível sobre seu conteúdo no alimento. Caso o ajuste da regressão seja bom, ou seja, não se verifiquem desvios de linearidade e a declividade da reta esteja próxima de 1 , considera-se que o componente é uma "entidade nutritiva ideal”.

Esses conceitos foram aplicados por Goering \& Van Soest (1970), que propuseram equações para predizer a digestibilidade aparente de forragens consumidas por ruminantes. O modelo proposto por esses autores é basicamente: $\mathrm{Y}=\mathrm{d}_{1}(\% \mathrm{CC})+\mathrm{d}_{2}(\% \mathrm{FDN})-\mathrm{E}$; em que: $\mathrm{d}_{1}=$ digestibilidade verdadeira do conteúdo celular (CC); $\mathrm{d}_{2}=$ digestibilidade verdadeira da fibra em detergente neutro
(FDN); e E = perda endógena de CC. Pagano-Toscano et al. (1986) propuseram um modelo para coelhos, com idêntica base teórica, ao compilar dados de diversos ensaios de digestibilidade; entretanto, não discutiram a estimação de $\mathrm{d}_{2}$.

O objetivo neste estudo foi obter equações baseadas no conceito de entidade nutritiva ideal que permitam predizer a digestibilidade da matéria seca de rações para coelhos em crescimento.

\section{Material e Métodos}

O experimento foi realizado no Coelhário do Biotério Central da UNESP - Campus de Botucatu - Rubião Junior. Foram usados 100 coelhos do Grupo Genético Botucatu, 50 machos e 50 fêmeas, com 42 dias de idade e peso inicial médio de $1.265 \mathrm{~g}(\mathrm{CV}=11,25 \%)$. Os animais foram alojados em gaiolas individuais providas de comedouro de barro e bebedouro automático.

Confeccionaram-se 16 rações experimentais peletizadas constituídas de um alimento volumoso mais os seguintes ingredientes (Tabela 1): farelo de soja, milho em grão, premix mineral e vitamínico, sal comum, caulim e óleo de soja. Os volumosos utilizados foram: papel Kraft, sabugo de milho, bagaço de cana e maravalha de pinheiro autoclavada. Os volumosos foram escolhidos por apresentarem diferentes graus de lignificação (proporção lignina/ FDN), alto teor de FDN e baixo teor de proteína bruta (PB). Todos os ingredientes foram moídos em peneira com crivo de $4 \mathrm{~mm}$. $\mathrm{Na}$ formulação das dietas (Tabela 2), cada volumoso participou em quatro níveis, de modo que se obtivessem rações com 16\% de PB e 22, 28, 34 ou 40\% de FDN. Devido à variação no teor de matéria seca dos ingredientes e a dificuldades ocorridas durante o processo de peletização, os teores de FDN das dietas experimentais ficaram abaixo dos esperados e os de PB apresentaram amplitude de 2,58 unidades percentuais (Tabela 3 ).

A energia digestível das rações experimentais foi estimada com base na equação proposta por De Blas et al.

Tabela 1 - Composição químico-bromatológica dos ingredientes utilizados nas rações experimentais

\begin{tabular}{|c|c|c|c|c|c|c|}
\hline \multirow[t]{2}{*}{ Ingrediente } & \multicolumn{6}{|c|}{ Componente $^{1}$ (\% da matéria seca) } \\
\hline & PB & FDN & FDA & Lignina & Celulose & Cinzas \\
\hline Milho em grão & 9,41 & 11,95 & 2,32 & 0,51 & 1,70 & 1,17 \\
\hline Farelo de soja & 49,55 & 14,10 & 9,42 & 1,17 & 8,16 & 6,38 \\
\hline Papel Kraft & 1,95 & 75,08 & 68,02 & 10,06 & 58,10 & 1,19 \\
\hline Sabugo de milho & 2,46 & 82,37 & 49,27 & 7,60 & 34,00 & 1,42 \\
\hline Bagaço de cana & 1,54 & 80,23 & 65,01 & 13,71 & 44,52 & 9,84 \\
\hline Maravalha de pínus & 0,91 & 89,00 & 75,24 & 7,64 & 67,15 & 0,13 \\
\hline
\end{tabular}

$\mathrm{PB}$ = proteína bruta; FDN = fibra em detergente neutro; FDA = fibra em detergente ácido. 
Tabela 2 - Composição percentual das rações experimentais

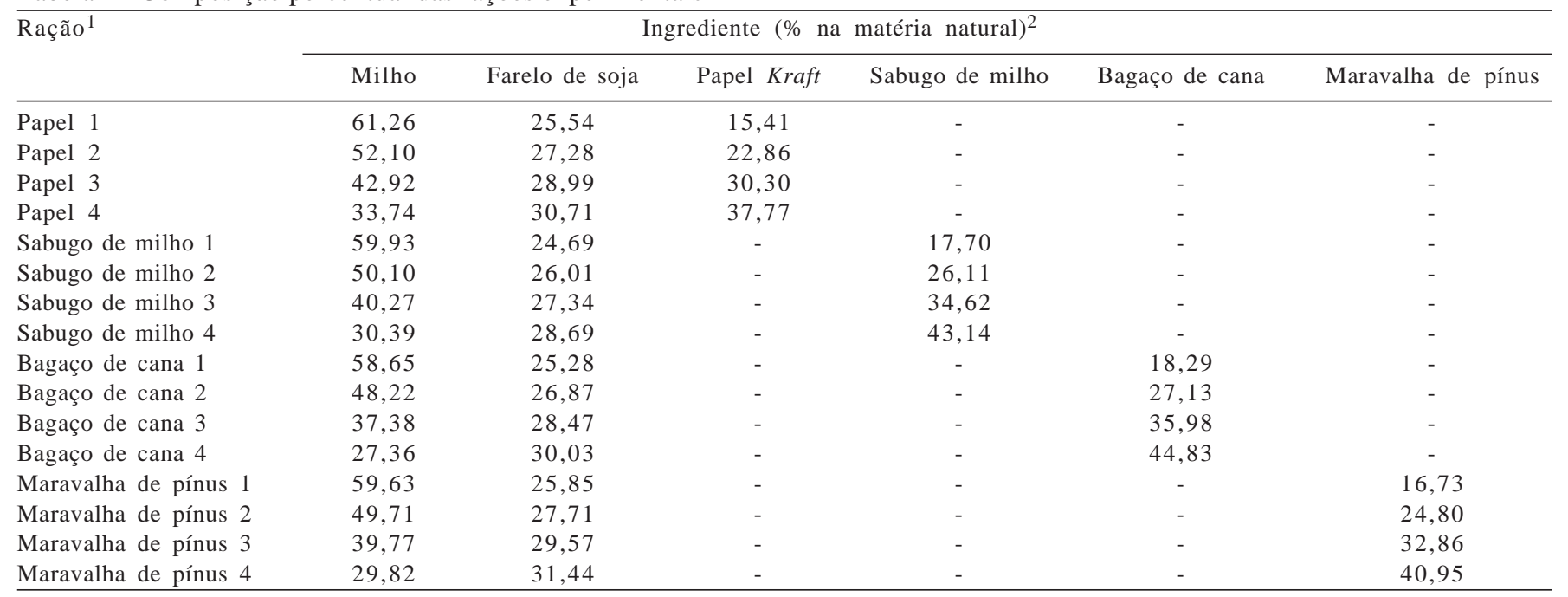

${ }^{1}$ Os números de 1 a 4 referem-se aos níveis pretendidos de FDN nas rações: 22, 28, 34 e 40\%, respectivamente.

2 Todas as rações continham $2 \%$ de óleo de soja, $5 \%$ de caulim , 0,5\% de sal comum e 0,5\% de premix vitamínico e mineral (Supervit Coelhos $5: 1$ ), com a seguinte composição (por kg), conforme informações do fabricante: vit. A - $1.875 .000 \mathrm{UI}$; vit. $\mathrm{D}_{3}-250.000 \mathrm{UI}$; vit. E - 12.500 mg; vit. $\mathrm{K}_{3}-750 \mathrm{mg}$; vit. $\mathrm{B}_{1}$ - 500 mg; vit. $\mathrm{B}_{2}-1.000 \mathrm{mg}$; vit. $\mathrm{B}_{12}-2.500 \mathrm{mcg}$; pantotenato de calcio - $2.000 \mathrm{mg}$; niacina - $5.000 \mathrm{mg}$; antioxidante - 25 g; coccidiostático - 25 g; cloreto de colina - 125 g; selênio - $15 \mathrm{mg}$; manganês - $60.000 \mathrm{mg}$; ferro - $80.000 \mathrm{mg}$; cobre - $12.000 \mathrm{mg}$; iodo - $5.000 \mathrm{mg}$; zinco - $50.000 \mathrm{mg}$.

Tabela 3 - Energia digestível estimada e composição quimicobromatológica das rações experimentais

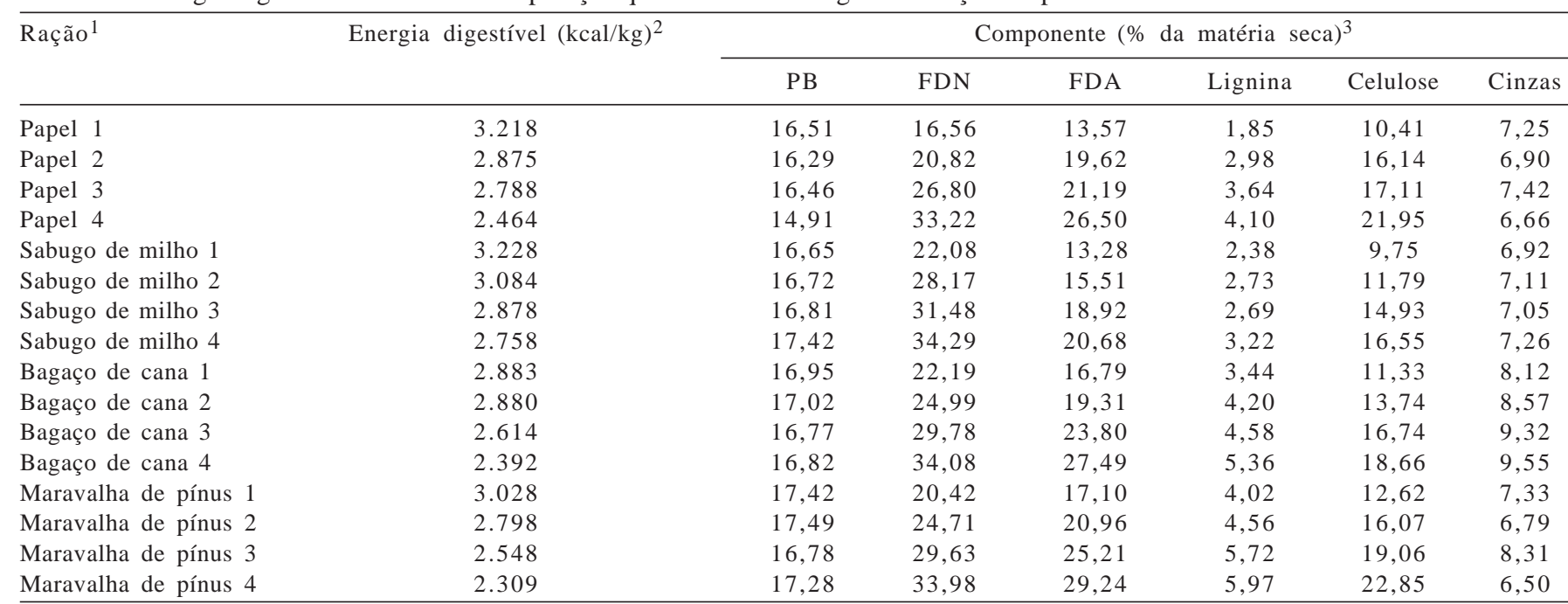

${ }^{1}$ Os números de 1 a 4 referem-se aos níveis pretendidos de FDN nas rações: 22, 28, 34 e 40\%, respectivamente.

${ }^{2} \mathrm{ED}=$ energia digestível estimada.

${ }^{3} \mathrm{~PB}=$ proteína bruta; FDN = fibra em detergente neutro; FDA = fibra em detergente ácido.

(1992). Usaram-se os teores de FDA determinados na análise químico-bromatológica das rações experimentais (Tabela 3) e o extrato etéreo estimado a partir dos valores apresentados por Rostagno et al. (2000) para o milho, farelo de soja e óleo de soja. Nesta estimativa, foi desconsiderado o extrato etéreo dos alimentos volumosos.

O experimento incluiu duas fases: na primeira foram usados 48 coelhos e na segunda 52 para que se obtivessem seis animais por tratamento (descontada a mortalidade). Cada fase foi composta de um período de adaptação de sete dias, seguido de um período experimental de quatro dias para colheita de ração e fezes.
Colheram-se as fezes com auxílio de uma tela de náilon amarrada nas laterais e fundos das gaiolas, formando um saco em forma de tronco de pirâmide, para permitir o escoamento da urina. As fezes foram colhidas e armazenadas em sacos plásticos mantidos em congelador.

Os coeficientes de digestibilidade aparente foram determinados segundo metodologia proposta por Perez et al. (1995). As amostras das rações e fezes foram submetidas a análises de FDN, FDA e lignina por permanganato (Goering \& Van Soest, 1970), bem como a análises dos conteúdos de matéria seca (MS), PB e cinzas (Silva, 1990), no Laboratório de Análises Bromatológicas da FMVZ 
(UNESP) Câmpus de Botucatu. O teor de conteúdo celular (CC) foi calculado por: 100 - \%FDN; e o de hemicelulose por: \%FDN - \%FDA.

Cada coelho constituiu uma unidade experimental. Os tratamentos foram sorteados entre os animais em cada fase. O delineamento empregado foi o de blocos (fases) ao acaso, com três repetições por ração em cada fase.

Os dados foram analisados por meio dos procedimentos GLMe REG do programa SAS, (1989). Inicialmente, aplicou-se aos dados de consumo de matéria seca (MS) o seguinte modelo:

$$
Y_{i j k}=m+F_{i}+R_{j}+b\left(P_{i j k}-\bar{P}\right)+e_{i j k}
$$

em que: $\mathrm{Y}_{\mathrm{ijk}}=$ consumo médio diário de matéria seca observado na i-ésima fase, j-ésima ração e k-ésimo coelho; $\mathrm{m}$ = efeito da média; $\mathrm{F}_{\mathrm{i}}=$ efeito da i-ésima fase; $\mathrm{R}_{\mathrm{j}}=$ efeito da j-ésima ração; $b$ = coeficiente de regressão; $\mathrm{P}_{\mathrm{ijk}}=$ peso do k-ésimo coelho (covariável); $\overline{\mathrm{P}}$... = média dos pesos; $\mathrm{e}_{\mathrm{ijk}}=$ erro aleatório, NID $\left(0, \sigma^{2}\right)$. O efeito de ração foi posteriormente desdobrado em efeito de volumoso, nível de FDN (regressão) e interação.

Aos dados de digestibilidade aparente aplicou-se o mesmo modelo, sem a covariável. Para obter uma equação empírica de predição da digestibilidade aparente da FDN, o efeito de rações foi substituído por uma regressão. As variáveis independentes que a constituíram foram escolhidas pelo método forward entre as seguintes: FDA, lignina, celulose, hemicelulose; as proporções destas na FDN; as razões entre a FDA e a lignina, celulose e hemicelulose; as razões entre a lignina e a celulose e hemicelulose; bem como os quadrados e logaritmos de todas estas variáveis. Mantiveram-se na regressão as variáveis significativas $(P<0,05)$. O coeficiente de determinação $\left(\mathrm{R}^{2}\right)$ desta regressão e das explanadas nos parágrafos seguintes foram calculadas por meio da relação entre a soma de quadrados da regressão e a soma de quadrados de rações. Em consequência, o $\mathrm{R}^{2}$ representa a proporção da variabilidade entre rações que pode ser explicada pela regressão; por outro lado, o coeficiente de variação (CV) quantifica a variabilidade dos valores individuais em torno da curva de regressão.

Aplicou-se o teste de uniformidade de Lucas (Van Soest, 1993) à PB, aos componentes fibrosos e ao conteúdo celular, mediante a regressão:

$$
\mathrm{Y}_{\mathrm{ijk}}=\mathrm{E}+\mathrm{F}_{\mathrm{i}}+\mathrm{dX} \mathrm{X}_{\mathrm{j}}+\mathrm{e}_{\mathrm{ijk}}
$$

em que: $Y_{i j k}=\%$ de componente digestível na j-ésima ração consumida na i-ésima fase pelo k-ésimo coelho; $\mathrm{E}$ = perda endógena ( $\mathrm{g} / 100 \mathrm{~g}$ MS consumida); $\mathrm{d}$ = digestibilidade verdadeira; $X_{j}=\%$ do componente na j-ésima ração; $F_{i} e$ $\mathrm{e}_{\mathrm{ijk}}=$ como anteriormente.

Com base nos resultados do teste de uniformidade, formulou-se um modelo aditivo (Goering \& Van Soest, 1970) para predizer a digestibilidade aparente da matéria seca (DAMS):

$$
\operatorname{DAMS}(\%)=\mathrm{d}_{1}(\% \mathrm{CC})+\mathrm{d}_{2}(\% \text { FDN })-\mathrm{E}
$$

em que: $\mathrm{d}_{1}=$ digestibilidade verdadeira do conteúdo celular, estimada no teste de uniformidade; $\mathrm{d}_{2}=$ digestibilidade verdadeira da FDN, empiricamente estimada; $\mathrm{E}=$ perda endógena de conteúdo celular, estimada no teste de uniformidade.

\section{Resultados e Discussão}

As médias das temperaturas mínima e máxima foram: 17 e $30{ }^{\circ} \mathrm{C}$; e 20 e $28{ }^{\circ} \mathrm{C}$, na primeira e segunda fase, respectivamente. A temperatura ambiente da segunda fase apresentou menor amplitude de variação e ficou mais próxima da zona de conforto para coelhos de 21 a $25{ }^{\circ} \mathrm{C}$, segundo Brody (1964), e de 15 a $21^{\circ} \mathrm{C}$ para animais de 80 dias de idade, de acordo com Cervera \& Fernandez-Carmona (1998).

Descartaram-se na primeira fase os dados de seis coelhos mortos por enterite, assim, as rações contendo bagaço de cana e maravalha com $40 \%$ de FDN foram avaliadas com cinco repetições e as demais com seis. Nesta mesma fase, observaram-se mais dois casos de enterite durante o período de adaptação, provavelmente decorrentes de estresse, que aumenta a incidência de diarreia nesta espécie (Carabaño et al., 2006).

O consumo médio de MS na primeira fase foi menor ( $\mathrm{P}<0,001)$ que na segunda $(79,8$ vs. 88,5 g/coelho/dia), diferença parcialmente explicável pelas menores temperaturas ocorridas na segunda fase. O conteúdo de FDN das rações teve efeito linear positivo $(\mathrm{P}<0,001)$ no consumo de MS (Tabela 4). Com o aumento no teor de fibra, diminui o teor de

Tabela 4 - Consumo de matéria seca das rações

\begin{tabular}{lc}
\hline Ração & Média de quadrados mínimos (g/coelho/dia) \\
\hline Papel 1 & 68,1 \\
Papel 2 & 71,5 \\
Papel 3 & 80,5 \\
Papel 4 & 83,9 \\
Sabugo de milho 1 & 68,6 \\
Sabugo de milho 2 & 88,1 \\
Sabugo de milho 3 & 87,4 \\
Sabugo de milho 4 & 110,3 \\
Bagaço de cana 1 & 87,8 \\
Bagaço de cana 2 & 79,0 \\
Bagaço de cana 3 & 90,7 \\
Bagaço de cana 4 & 99,2 \\
Maravalha de pínus 1 & 70,8 \\
Maravalha de pínus 2 & 74,7 \\
Maravalha de pínus 3 & 86,7 \\
Maravalha de pínus 4 & 99,8 \\
Coeficiente de variação (\%) & 19,95 \\
\hline Os números de 1 a 4 referem-se aos níveis pretendidos de FDN nas rações: 22, 28, \\
34 e 40\%, respectivamente.
\end{tabular}

R. Bras. Zootec., v.40, n.12, p.2783-2790, 2011 
energia digestível e aumenta a velocidade de trânsito do alimento no trato digestivo. Consequentemente, o consumo aumenta para que se mantenha constante a ingestão de energia digestível (Gidenne, 2003).

As médias dos coeficientes de digestibilidade aparente da MS, FDN, FDA, lignina e celulose foram maiores $(\mathrm{P}<0,01)$ na segunda fase, enquanto a digestibilidade da PB, FDA e hemicelulose não foi afetada pelas fases.

Diferenças entre os grupos foram observadas $(\mathrm{P}<0,01)$ para os coeficientes de digestibilidade aparente de MS, FDN, lignina e celulose (Tabela 5). Os coeficientes de variação foram baixos para as digestibilidades da MS e PB, porém bem mais elevados para os demais componentes. Ademais, obtiveram-se vários coeficientes negativos para a hemicelulose e valores negativos para a lignina. Segundo Gidenne (2003), o coeficiente médio de digestibilidade da lignina em coelhos está entre 10 e $15 \%$ e pode variar entre $-13 \%$ e $50 \%$. Os valores negativos obtidos neste experimento para a lignina foram, no entanto, muito mais extremos. Fahey Junior et al. (1980) postularam uma explicação para os coeficientes de digestibilidade negativos da lignina em ovinos. De acordo com esses autores, a lignina e outros compostos fenólicos vegetais seriam degradados na passagem pelo trato intestinal dos animais e os ácidos fenólicos resultantes desta degradação ligar-se-iam a fragmentos de nitrogênio e seriam excretados, contribuindo para a recuperação de grande quantidade de lignina das fezes. Mecanismo semelhante poderia ter ocorrido nos coelhos, resultando em coeficientes negativos de digestibilidade da lignina.
Os altos coeficientes de digestibilidade obtidos para os componentes fibrosos refletem a alta variabilidade entre os animais na capacidade de digestão da fibra. Os coeficientes de digestibilidade negativos observados para a hemicelulose são atribuídos aos baixos teores deste componente nas rações contendo maravalha. Estes altos coeficientes de variação também podem estar relacionados a prováveis erros laboratoriais nas análises de FDN, FDA e lignina.

Um desdobramento do efeito dos níveis de FDN da ração na digestibilidade aparente da MS revelou efeito linear negativo $(\mathrm{P}<0,001)$ da FDN e interação $(\mathrm{P}<0,05)$ entre teor de FDN e volumoso. A diminuição da digestibilidade da MS ocasionada pela elevação no teor de fibra está diretamente relacionada ao aumento da velocidade de trânsito no trato digestório como um todo (Aderibigbe, 1992; Gidenne et al., 1998).

Desdobramento semelhante mostrou efeito linear negativo $(\mathrm{P}<0,05)$ da FDN na digestibilidade aparente da $\mathrm{PB}$, embora as diferenças tenham sido pequenas e sem importância prática (Tabela 5). De Blas et al. (1986) observaram efeito negativo maior da FDN sobre a digestibilidade aparente da PB; todavia, nas rações testadas por estes autores, o teor de $\mathrm{PB}$ diminuiu à medida que aumentou o de FDN. Por outro lado, Sartika \& Raharjo (1992), trabalhando com rações isonitrogenadas, não encontraram efeito da fibra sobre a digestibilidade aparente da PB. Gidenne et al. (1998) também relataram efeito do teor de lignina sobre esta mesma variável. O coeficiente de digestibilidade da PB das forragens

Tabela 5 - Médias dos quadrados mínimos das digestibilidades

\begin{tabular}{|c|c|c|c|c|c|c|c|}
\hline \multirow[t]{2}{*}{ Ração } & \multicolumn{7}{|c|}{ Coeficiente de digestibilidade aparente (\%) } \\
\hline & MS & $\mathrm{PB}$ & FDN & FDA & Hemicelulose & Lignina & Celulose \\
\hline Papel 1 & 80,78 & 87,04 & 20,17 & 24,25 & 45,96 & $-329,3$ & 71,77 \\
\hline Papel 2 & 78,30 & 89,67 & 21,25 & 29,33 & $-94,53$ & $-271,7$ & 84,33 \\
\hline Papel 3 & 72,79 & 87,95 & 19,86 & 13,99 & 40,96 & $-294,2$ & 81,04 \\
\hline Papel 4 & 65,27 & 85,97 & 16,23 & 6,02 & 41,07 & $-397,5$ & 89,82 \\
\hline Sabugo de milho 1 & 76,13 & 86,38 & 27,99 & 27,27 & 81,45 & $-198,2$ & 35,96 \\
\hline Sabugo de milho 2 & 70,88 & 86,18 & 23,94 & 18,73 & 83,36 & $-258,6$ & 25,22 \\
\hline Sabugo de milho 3 & 64,03 & 86,53 & 12,42 & 14,43 & 79,37 & $-355,8$ & 23,78 \\
\hline Sabugo de milho 4 & 59,97 & 84,76 & 11,75 & 12,22 & 71,48 & $-333,2$ & 26,79 \\
\hline Bagaço de cana 1 & 73,91 & 87,57 & 21,39 & 19,73 & 65,31 & $-145,7$ & 65,01 \\
\hline Bagaço de cana 2 & 69,48 & 86,77 & 16,39 & 17,67 & 44,59 & $-157,3$ & 63,67 \\
\hline Bagaço de cana 3 & 61,45 & 85,37 & 9,42 & 10,19 & 32,15 & $-215,1$ & 66,58 \\
\hline Bagaço de cana 4 & 58,88 & 87,80 & 12,67 & 13,83 & 23,21 & $-191,1$ & 67,50 \\
\hline Maravalha de pínus 1 & 76,32 & 89,96 & 13,20 & 20,54 & 7,46 & $-147,3$ & 67,19 \\
\hline Maravalha de pínus 2 & 70,78 & 87,58 & 10,21 & 20,53 & $-6,20$ & $-158,6$ & 65,50 \\
\hline Maravalha de pínus 3 & 66,23 & 87,05 & 8,89 & 13,12 & $-20,69$ & $-175,9$ & 73,20 \\
\hline Maravalha de pínus 4 & 60,10 & 85,72 & 8,58 & 10,21 & $-54,18$ & $-204,1$ & 78,72 \\
\hline Coeficiente de variação (\%) & 4,99 & 3,02 & 55,19 & 54,08 & 54,79 & 16,68 & 15,12 \\
\hline
\end{tabular}

Os números de 1 a 4 se referem aos níveis pretendidos de FDN nas rações: 22, 28, 34 e 40\%, respectivamente.

MS = matéria seca; $\mathrm{PB}$ = proteína bruta; FDN = fibra em detergente neutro; FDA = fibra em detergente ácido. 
consumidas por coelhos proposto por De Blas et al (1984) foi $58 \%$ e o dos concentrados proteicos, 74,5\% (De Blas et al., 1984); entretanto, esses autores parecem não ter considerado que, em várias espécies, a digestibilidade verdadeira da $\mathrm{PB}$ é constante, mas a aparente diminui conforme o teor deste nutriente diminui (Fraga, 1998). Neste estudo, os teores de PB das rações foram semelhantes e não houve correlação destes com os componentes fibrosos $(\mathrm{P}>0,10)$, portanto, não poderia ter ocorrido confundimento entre teor de $\mathrm{PB}$ e de fibra. Fekete \& Bokori (1985) mostraram que, à medida que aumenta a diferença entre o teor de fibra e o teor de PB da dieta, o coelho consome maior proporção dos cecotrofos, o que lhe permitiria compensar, até certo ponto, o efeito deletério da fibra sobre a digestão da PB. Este fato ajudaria a explicar algumas discrepâncias encontradas na literatura sobre a digestão de PB.

A digestibilidade média da FDN oscilou entre 8,58 e $27,99 \%$ e a da FDA entre 6,02 e 29,33\% (Tabela 5). Os valores foram baixos em comparação aos obtidos por Pagano-Toscano et al. (1986) entre 13,66 e 58,82\% para FDN; e entre 8,91 e 65,78\% para a FDA. Esses autores trabalharam com uma amplitude de FDN semelhante à deste estudo, porém a média foi mais alta $(45,7 \%)$ e a fibra provinha predominantemente de alfafa, resíduo de uvas e farelo de trigo, que são ingredientes tradicionalmente usados em rações para coelhos, ao contrário dos empregados nesta pesquisa. Por outro lado, Pinheiro et al. (2009), em trabalho com uma dieta de baixo (24,8\% de FDN e $16,8 \%$ de FDA) e outra de alto teor de fibra (32,3\% de FDN e $23,3 \%$ de FDA), relataram pequena variação nos coeficientes de digestibilidade aparente destas frações: $27,6 \%$ e $29,7 \%$, respectivamente, para a FDA e 36,5 e 36,1\%, respectivamente, para a FDN. No entanto, as dietas usadas no estudo possuíam composição complexa da fração fibrosa, incluindo diversas fontes de fibras de digestibilidade variada, como alfafa desidratada, polpa cítrica, polpa de beterraba, farelo de trigo e farelo de semente de uvas. Talvez esta variedade de ingredientes fibrosos possa explicar, em parte, a baixa amplitude de coeficientes de digestibilidade da FDA e da FDN.

Duas equações empíricas foram obtidas para predizer a digestibilidade aparente da FDN (Tabela 6). A primeira equação é mais simples e não inclui todas as variáveis significativas $(\mathrm{P}<0,05)$ : traduz o efeito negativo do teor de FDA na digestibilidade da FDN. A segunda equação, mais complexa e com melhor ajuste, inclui também o efeito da proporção de lignina na FDN. Goering \& Van Soest (1970) propuseram uma equação para estimar a digestibilidade da FDN em ruminantes, baseada na proporção de lignina na FDA. O teor de lignina na parede celular sabidamente interfere na digestibilidade da celulose e hemicelulose das forragens fornecidas a ruminantes (Van Soest, 1993); também em coelhos nota-se influência negativa da lignina na digestibilidade da fibra (Cheeke, 1987; Gidenne et al., 1998).

Segundo o teste de uniformidade de Lucas (Van Soest, 1993), a PB e o conteúdo celular estão próximos do conceito de entidade nutritiva ideal, por apresentarem altos $R^{2}(0,84$ e 0,95 , respectivamente) e baixos coeficientes de variação (3,22 e 2,89\%, respectivamente, Tabela 7). Dessa forma, pode-se admitir que a digestibilidade verdadeira desses dois componentes é constante, e também que a perda endógena é uma fração constante da ingestão de MS. A digestibilidade verdadeira estimada da PB $(0,89)$ foi próxima aos valores da literatura (Maynard et al., 1979; McDonald et al., 1988) para ruminantes e monogástricos (em torno de 0,9). Por outro lado, a perda endógena estimada $(0,36 \mathrm{~g} / 100 \mathrm{~g}$ MS ingerida) ficou abaixo dos valores relatados para ruminantes (cerca de 3 g/100 g) e suínos (0,6 a 1,25 g/100 g). Deve-se levar em conta, entretanto, que a amplitude da PB nas dietas neste estudo foi pequena (2,58 unidades percentuais). A digestibilidade verdadeira estimada do conteúdo celular foi 1,192 e diferente $(\mathrm{P}<0,001)$ do máximo teórico $(1,000)$; a perda endógena estimada desta fração foi 21,95 g/100 g MS ingerida (Tabela 7). Goering \& Van Soest (1970) propuseram 0,98 para a digestibilidade verdadeira e 12,9 g/100 g para a perda endógena do conteúdo celular de forragens consumidas por ovinos, enquanto Pagano-Toscano et al. (1986) propuseram 0,78 e 8,73 g/100 g, respectivamente, para rações completas consumidas por coelhos machos de 12 semanas de idade. As diferenças entre esses estudos poderiam ser, em parte, devidas à menor idade dos animais (seis semanas).

Como esperado, a FDN, FDA, lignina, hemicelulose e celulose não puderam ser consideradas entidade nutritiva

Tabela 6 - Equações de predição da digestibilidade da FDN

\begin{tabular}{cccccc}
\hline Modelo & $\mathrm{b}_{0}$ & \multicolumn{3}{c}{ Variável independente } & \multirow{2}{*}{$\mathrm{R}^{2}$} \\
\cline { 3 - 5 } & & $\ln ($ FDA $)$ & $($ Lignina/FDN) & $\ln ($ lignina/FDN) & \\
\hline 1 & 71,18 & $-18,45$ & & & 0,74 \\
2 & 186,6 & $-18,02$ & -1277 & 44,99 & 56,28 \\
\hline
\end{tabular}

FDN = fibra em detergente neutro; FDA = fibra em detergente ácido; $C V$ = coeficiente de variação. 
idel, pois apresentaram altos coeficientes de variação e baixos $\mathrm{R}^{2}$, de acordo com o teste de uniformidade de Lucas (Tabela 7). Os quesitos do teste incluem coeficiente de digestibilidade verdadeiro constante (por isso a demanda de alto $\mathrm{R}^{2}$ e baixo coeficiente de variação), independentemente da fonte alimentar e do nível de consumo, e intercepto menor ou igual a zero, o que indicaria perda metabólica fecal maior ou igual a zero. No caso em pauta, as frações FDN e FDA produziram intercepto positivo, o que indica contribuição metabólica fecal negativa, que é impossível. Esses fatos refletem a desuniformidade na composição da parede celular, que afeta a digestibilidade desses componentes.

Com base nos resultados (Tabelas 6 e 7), formularam-se três modelos aditivos para predizer a digestibilidade aparente da MS, admitindo-se que o conteúdo celular tenha $100 \%$ de digestibilidade verdadeira e que sua perda endógena seja 21,95 g/100 g de MS consumida. Quanto ao $\mathrm{R}^{2}$ e coeficiente de variação, os modelos pouco diferiram e apresentaram bom ajuste, embora o terceiro tenha-se mostrado ligeiramente melhor (Tabela 8). Todavia, o primeiro modelo apresentou $\mathrm{b}_{0}$ estimado diferente de zero $(\mathrm{P}<0,01)$, o que é indesejável. Os outros dois apresentaram valores de $\mathrm{b}_{0}$ menores e não diferentes $(\mathrm{P}>0,10)$ de zero. Por outro lado, todos os modelos tiveram $\mathrm{b}_{1}$ estimados maiores que $1(\mathrm{P}<0,01)$, o que também não é desejável. No cômputo geral, o terceiro modelo parece ser o mais adequado. Pagano-Toscano et al. (1986) propuseram um modelo aditivo semelhante, mas não indicaram como estimar, ainda que empiricamente, a digestibilidade da FDN.

A pequena contribuição ao ajuste, decorrente da inclusão da digestibilidade da FDN, justifica-se pelo teor de fibra das rações estudadas, que não atingiu altos valores. Não obstante, os teores de FDN deste estudo abrangeram os valores mais comumente empregados na alimentação de coelhos em crescimento.

Tabela 7 - Resultados do teste de uniformidade de Lucas

\begin{tabular}{|c|c|c|c|c|c|c|}
\hline Componente & $\mathrm{b}_{0}$ & $\mathrm{H}_{0}: \mathrm{b}_{0}=0$ & $\mathrm{~b}_{1}$ & $\mathrm{H}_{0}: \mathrm{b}_{1}=1$ & $\mathrm{R}^{2}$ & $\mathrm{CV}(\%)$ \\
\hline Conteúdo celular ${ }^{1}$ & $-21,95$ & $\mathrm{P}<0,001$ & 1,192 & $\mathrm{P}<0,001$ & 0,95 & 2,89 \\
\hline Fibra em detergente neutro & 3,947 & $\mathrm{P}<0,01$ & 0,007886 & $\mathrm{P}<0,001$ & 0,00 & 56,35 \\
\hline Hemicelulose & $-3,811$ & $\mathrm{P}<0,001$ & 1,0586 & $\mathrm{P}>0,10$ & 0,89 & 47,95 \\
\hline Lignina & $-4,430$ & $\mathrm{P}<0,001$ & $-1,1262$ & $\mathrm{P}<0,001$ & 0,19 & 34,22 \\
\hline Celulose & $-6,760$ & $\mathrm{P}<0,001$ & 1,0716 & $\mathrm{P}<0,001$ & 0,67 & 31,07 \\
\hline
\end{tabular}

${ }_{1} 100-$ FDN.

Tabela 8 - Teste dos modelos aditivos para predição da digestibilidade aparente da matéria seca

\begin{tabular}{cccccc}
\hline Modelo & $\mathrm{b}_{0}$ & $\mathrm{H}_{0}: \mathrm{b}_{0}=0$ & $\mathrm{~b}_{1}$ & $\mathrm{H}_{0}: \mathrm{b}_{1}=1$ & $\mathrm{R}$ \\
\hline 1 & 8,775 & $\mathrm{P}<0,01$ & 1,184 & $\mathrm{P}<0,01$ & 0,90 \\
2 & 3,975 & $\mathrm{P}>0,10$ & 1,182 & $\mathrm{P}<0,01$ & 4,78 \\
3 & 4,529 & $\mathrm{P}>0,10$ & 1,172 & $\mathrm{P}<0,01$ & 0,90 \\
\hline
\end{tabular}

O modelo 1 só inclui o conteúdo celular; os modelos 2 e 3 incluem também a digestibilidade da FDN, predita pelas equações 1 e 2, respectivamente (Tabela 6). $\mathrm{CV}=$ coeficiente de variação. No modelo 1, dispensou-se a contribuição da FDN. No modelo 2, incluiu-se a contribuição da FDN, com digestibilidade predita pela primeira equação. No modelo 3, a digestibilidade da FDN foi predita pela segunda equação.

\section{Conclusões}

A principal dificuldade na formulação de modelos para predizer a digestibilidade aparente da MS em coelhos ainda consiste em estimar com precisão a digestibilidade da fibra em detergente neutro e a perda endógena de conteúdo celular. São necessários estudos com inclusão de níveis mais altos de fibra nas rações. Para rações com níveis de fibra situados na amplitude testada neste estudo, recomenda-se usar o modelo 3 , que inclui, além da fibra em detergente neutro, fibra em detergente ácido e lignina.

\section{Agradecimentos}

A todos os funcionários do Biotério Central do Laboratório de Análises Bromatológica da Fábrica de Ração, pelo auxílio na execução deste trabalho.

\section{Referências}

ADERIBIGBE, A.O.; GAD, A.; CHEEKE, P.R. et al. Effect of supplementing weanling rabbit diets with untreated annual ryegrass straw as fiber sources on performance and nutrient digestibility. Journal of Applied Rabbit Research, v.15, p.1189-1195, 1992 
BRODY, S. Bioenergetics and growth. New York: Hafner, 1964. $1023 p$.

CARABAÑO, R.; BADIOLA, I.; LICOIS, D. et al. The digestive ecosystem and its control through nutritional or feeding strategies. In: MAERTENS, L.; COUDERT, P. (Eds.) Recent advances in rabbit sciences. Merelbeke: ILVO, 2006. p.211-227.

CERVERA, C.; FERNÁNDEZ-CARMONA, J. Climatic Environment. In: De BLAS, C., WISEMAN, J. (Eds.) The nutrition of the rabbit. Cambridge: CABI. 1998. p.273-295.

CHEEKE, P.R. Rabbit feeding and nutrition. Orlando: Academic Press, 1987. 380p.

DE BLAS, J.C.; FRAGA, M.J.; RODRIGUEZ, J.M. et al. The nutritive value of feeds for growing fattening rabbits 2. Protein evaluation. Journal of Applied Rabbit Research, v.7, p.97-100, 1984.

DE BLAS, J.C.; WISEMAN, J.; FRAGA, M.J. et al. Prediction of digestible energy and digestibility of gross energy of feeds for rabbits. 2. Mixed diets. Animal Feed Science and Technology, v.39, p.39-59, 1992.

DE BLAS, J.C.; SANTOMÁ, G.; CARABAÑO, R. et al. Fiber and starch levels in fattening rabbits diets. Journal of Animal Science, v.63, p.1897-1904, 1986.

FAHEY JUNIOR, G.C.; AL-HAYADARI, S.Y.; HINDS, F.C. et al. Phenolic compounds in roughages and their fate in the digestive system of sheep. Journal of Animal Science, v.50, p.1165-1172, 1980.

FEKETE, S.; BOKORI, J. The effect of the fiber and protein level of the ration upon the cecotrophy of rabbit. Journal of Applied Rabbit Research, v.8, n.2, p.68-71, 1985.

FERREIRA, W.M.; SAAD, F.M.O.B.; PEREIRA, R.A.N. Fundamentos da Nutrição de coelhos. In: CONGRESSO DE CUNICULTURA DAS AMÉRICAS, 3., 2006, Maringá. Anais... Maringá: American Branch of the World Rabbit Science Association. [2006]. (CD-ROM).

FRAGA, M.J. Protein digestion. In: DE BLAS, C.; WISEMAN, J. (Eds.) The nutrion of the rabbit. Cambridge: CABI, 1998. p.39-53.

GIDENNE, T.; CARABAÑO, R.; GARCIA, J. et al. Fibre digestion. In: DE BLAS, C.; WISEMAN, J. (Eds.) The nutrion of the rabbit. Cambridge: CABI, 1998. p.69-88.
GIDENNE, T. Fibres in rabbit feeding digestive troubles prevention: respective role of low-digested and digestible fibre. Livestock Production Science, n.81, p.105-117, 2003.

GOERING, H.K.; VAN SOEST, P.J. Forage fiber analyses. Beltsville: USDA, 1970. 20p. (Agriculture Handbook n.379).

MAYNARD, L.A.; LOOSLI, J.K.; HINTZ, H.F. et al. Animal nutrition. 7.ed. New York: McGraw-Hill, 1979. 602p.

MCDONALD, P.; EDWARDS, R.A.; GREENHALH, J.F.D. Animal nutrition. 4.ed. New York: Longman, 1988. 543p.

PAGANO-TOSCANO, G.; BENATTI, G.; ZOCCARATO, T. Comparison of crude fiber and the Van Soest methods for fiber determination in rabbit feeds. Journal of Applied Rabbit Research, v.9, p.69-75, 1986.

PEREZ, J.M.; LEBAS, F.; GIDENNE, T. et al. European reference method for in vivo determination of diet digestibility in rabbits. World Rabbit Science, v.3, n.1, p.41-43, 1995.

PINHEIRO, V.; GUEDES, C.M.; OUTOR-MONTEIRO, D. et al. Effects of fibre level and dietary mannanologosaccharides on digestibility, caecal volatile fatty acids and performances of growing rabbits. Animal Feed Science and Technology, n.148, p.288-300, 2009.

ROSTAGNO, H.S.; ALBINO, L.F.T.; DONZELE, J.L. et al. Tabelas brasileiras para aves e suínos: composição de alimentos e exigências nutricionais. Viçosa, MG: UFV. 2000. $141 \mathrm{p}$.

SARTIKA, T.; RAHARJO, Y.C. Effects of various fiber levels on the performance carcass, percentage and skin quality of the Rex Rabbits. Journal of Applied Rabbit Research, v.15, p.1583-1589, 1992.

SAS Institute Inc. SAS/STAT user's guide, version 6. 4.ed., v.2. Cary: 1989. 846p.

SILVA, D.J. Análise de alimentos (métodos químicos e biológicos) Viçosa, MG: Imprensa Universitária. 1990. 165p.

VAN SOEST, P.J. Cell wall matrix interactions and degradation. In: JUNG, H.G.; BUXTON, D.R.; HATFIELD, R.D. et al. (Eds.) Forage cell wall structure and digestibility. Madison: ASACSSA-SSSA, 1993. p.377-395. 